\title{
ANÁLISE POSTURA E DE DESCONFORTO MUSCULOESQUELÉTICO EM TRABALHADORES DE MÁQUINA DE OFF SET: ESTUDO DE CASO
}

\section{POSTURAL ANALYSIS AND MUSCULOSKELETAL DISCOMFORT IN OFF SET MACHINE WORKERS: CASE STUDY}

\author{
Tiago Balie \\ Odair Augusto Totino \\ Wilson Viana da Silva \\ Rosangela Monteiro dos Santos \\ Flavio Cardoso Ventura \\ FATEC - Faculdade de Tecnologia de Jahu \\ e-mail: balie tiago@hotmail.com
}

Palavras-chave: Trabalho em pé; máquina impressora off set; método OWAS.

A postura em pé causa diversos constrangimentos posturais. Este estudo teve a finalidade de realizar uma análise dos aspectos ergonômicos referentes a postura utilizada e ao desconforto muscular no trabalho da máquina off set de três funcionários. Constatou-se que o trabalho possui atividades que oferece sobrecargas posturais que ocasionam sintomas no segmento lombar da coluna vertebral, traduzidos em categorias de risco, sendo necessárias algumas mudanças nos métodos de trabalho.

Keywords: Standing Work, Off Set Printing Machine, Owas Method

Abstract

The standing posture can cause many postural problems. This study aimed to carry out an analysis of ergonomic aspects related to the way of the use of the posture and muscle discomfort at work to three employees at the machine off set. It was noticed that the work has activities that provides postural overloads that cause symptoms in the lumbar segment of the spine, translated into risk categories. It needs some changes in working method. 


\section{$16^{\circ}$ \\ ERGODESIGN USIHC CINAHPA}

\section{Introdução}

Na sociedade moderna o homem vem sendo cada vez mais solicitado a cumprir com eficiência o seu trabalho. Suas atividades são cada vez mais especializadas e complexas. Isto implica dizer que tanto o trabalho que requer uma maior exigência física quanto o trabalho de maior exigência mental podem provocar sobrecargas no seu organismo. Dentre estas sobrecargas impostas ao trabalhador destacam-se as posturais, que consequentemente podem levar ao acometimento de algum tipo de constrangimentos musculoesqueléticos.

Os operadores das máquinas offset devido ao tipo de atividade laboral que executam, ou seja, de ciclo de tarefa repetitiva onde permanecem na postura em pé durante todo o seu processo de trabalho com manutenção de postura estática e por vezes, dinâmica, por períodos de tempo prolongado, realizam movimentos de esforço para a coluna vertebral por terem que executar suas atividades com o tronco inclinado.

Considerando tais informações, é relevante investigar as condições de trabalho e saúde neste setor.

\subsection{Objetivos}

Realizar uma análise dos aspectos ergonômicos relacionados a identificar as posturas corporais constrangedoras nas atividades profissionais do operador impressor em máquina offset, utilizando o Método OWAS (Ovaco Working Posture System) e avaliar a prevalência de dor e/ou desconforto muscular de três funcionários.

\section{Referencial teórico}

As atividades dos operadores de máquinas offset impõem uma sobrecarga postural, pois a dor nas costas devido a essa sobrecarga causa prejuízo ao equilíbrio musculoesquelético do corpo do trabalhador, constituindo, conforme o Ministério do Trabalho e Emprego, uma das maiores causas de afastamento do trabalho e sofrimento dos trabalhadores, pois o ciclo de tarefa repetitiva onde $16^{\circ}$ Ergodesign - Congresso Internacional de Ergonomia e Usabilidade de Interfaces Humano Tecnológica: Produto, Informações Ambientes Construídos e Transporte

$16^{\circ}$ USIHC - Congresso Internacional de Ergonomia e Usabilidade de Interfaces Humano Computador

CINAHPA | 2017 - Congresso Internacional de Ambientes Hipermídia para Aprendizagem. permanecem na postura em pé durante todo o seu processo de trabalho com manutenção de postura estática e por vezes, dinâmica, por períodos de tempo prolongado, realizam movimentos de esforço para a coluna vertebral por terem que executar suas atividades com o tronco inclinado (CEZAR, 2006).

O corpo na posição em pé traduz uma postura mais fatigante em relação às outras posturas, pois existe um grande trabalho estático da musculatura mantenedora e uma maior solicitação energética do corpo. Uma pessoa pode estar na posição deitada, sentada, em pé com a coluna retificada, ajoelhada ou agachada, ou em pé com o tronco inclinado para frente. Nesta ordem, aumenta a solicitação energética do corpo devido à posição adotada.

O trabalho realizado sob condições inadequadas obriga o trabalhador a intensos e inadequados movimentos da coluna, membros superiores, região escapular e pescoço, levando frequentemente aos sintomas musculoesqueléticos, representando um sério problema de saúde pública, sendo uma das mais importantes causas de incapacidades e absenteísmo em trabalhadores (SANTOS FILHO e BARRETO, 2001).

Os sintomas musculoesqueléticos têm sido associados aos efeitos dos fatores de risco presentes nas situações ocupacionais como as tarefas repetitivas e monótonas, obrigações em manter o ritmo acelerado, excesso de horas trabalhadas e ausência de pausas, má iluminação, temperatura inadequada, ruídos, dificuldade de relacionamentos interpessoais, pressão da chefia, cumprimento de metas para maior produtividade $\mathrm{e}$ fantasma do desemprego, posturas e movimentos inadequados dentre outros.

A relevância de estudos que visem à avaliação e prevenção de desconforto musculoesquelético em situações ocupacionais reside no fato de que tais fatores geram consequências sociais e econômicas, tanto para o Estado como para as empresas (De Vitta, 1999). Para a empresa, significa a redução no número de homens/horas trabalhada, devido à ausência do trabalho por períodos de tempo consideráveis o que provoca uma perda na

Realização:




\section{$16^{\circ}$ \\ ERGODESIGN USIHC CINAHPA}

produtividade e na qualidade do serviço. Para o Estado, as despesas recaem sobre o INSS, e decorrem do pagamento de benefícios previdenciários. Além do benefício pago aos acidentados ou dependentes, as despesas de tratamento e reabilitação correm por conta do INSS.

O setor de offset representa a última etapa dos processos de impressão gráfica. A impressora é um mecanismo destinado a colocar em contato, sob pressão, uma chapa entintada e uma folha de papel. Ela comprime o papel contra o dispositivo de impressão. Em sua forma mais simples, uma impressora consiste de duas superfícies planas que podem ser justapostas sob pressão. A chapa e o papel são colocados entre essas superfícies, aplicando-se pressão, de modo que o papel receba a tinta da chapa. Esta ação produz uma impressão, chamada de "impressão indireta", se comparada com o processo de impressão tipográfica.

Uma das ferramentas para análise da postura em pé é o OWAS. É um método utilizado para identificar, registrar e analisar as posturas adotadas pelos trabalhadores em seu local de trabalho. Sua nomenclatura "OWAS" deriva-se de Ovako Working Posture Analysing System e foi proposto por três pesquisadores finlandeses (KARKU; KANS; KUORINKA, 1977), em conjunto com o Instituto Finlandês de Saúde Ocupacional. Eles encontraram 72 posturas típicas que resultaram em diferentes combinações das posições das costas, braços e pernas nos trabalhadores avaliados.

\section{Metodologia}

Foi realizado um estudo de caso no setor de offset em uma empresa gráfica em uma cidade do interior de São Paulo.

Primeiramente foi solicitado permissão para a realização do estudo na empresa. Após a assinatura do Termo de Consentimento Livre e Esclarecido pelos participantes de acordo com o Comitê de Ética foram coletados os dados.

Foram avaliados os posicionamentos corporais, através da ferramenta OWAS digital e do software $16^{\circ}$ Ergodesign - Congresso Internacional de Ergonomia e Usabilidade de Interfaces Humano Tecnológica: Produto, Informações Ambientes Construídos e Transporte

$16^{\circ}$ USIHC - Congresso Internacional de Ergonomia e Usabilidade de Interfaces Humano Computador

CINAHPA | 2017 - Congresso Internacional de Ambientes Hipermídia para Aprendizagem.

da Ergolândia. Os segmentos corporais avaliados foram: costas, braços e pernas.

Os sintomas musculoesqueléticos foram analisados através do questionário nórdico de sintomas musculoesqueléticos. O questionário é composto por três perguntas principais que referem-se a questão se a pessoas sentiu dor ou desconforto nos último 30 dias, últimos 12 meses e se deixou de realizar alguma atividade no cotidiano decorrente a essa dor ou desconforto. A localização da dor ou desconforto é avaliada através de demonstração visual de um mapa da região anterior e posterior do corpo com todos os segmentos corporais.

\section{Resultados e Discussão}

Para desenvolver as suas atividades, o operador da impressora offset dispõe de um ferramental variado, tanto no trabalho diretamente relacionado à impressão (ao redor da máquina), quanto no trabalho auxiliar de todo esse processo.

Existem diversas atividades de trabalho diretamente relacionadas à impressão que fazem parte das tarefas do operador da máquina, com bastante variabilidade de tempo entre uma e outra, gerando variados ciclos de atividade.

Durante sua jornada de trabalho, o operador da máquina offset realiza toda sua atividade de imprimir na posição em pé e circula ao redor das máquinas diversas vezes, controlando o processo, regulando a máquina e tirando as "provas" para conferência. Todo este procedimento lhe é bastante cansativo.

Obteve-se um total de seis posturas na observação sistemática das atividades de processo direto de impressão dos operadores das máquinas offset. A soma do tempo total de ações (as seis posturas obtidas) também é bastante variável, sendo que na observação feita para a realização desta pesquisa, foi de quarenta e quatro minutos, em uma sequência lógica de ações para obter o impresso pronto. Cabe aqui ressaltar, que a sequência completa de ações desde o início do seu trabalho até a obtenção do impresso pronto é muito maior que a apresentada aqui, porém, as seis posturas já 


\section{$16^{\circ}$ \\ ERGODESIGN USIHC CINAHPA}

citadas foram obtidas como sendo de maiores riscos musculoesqueléticos para referentes ao processo direto de impressão.

O operador de máquina offset, utiliza, para o desenvolvimento do seu trabalho de imprimir, quatro dos cinco sentidos sensoriais que possui:

1. A máquina apresenta diferentes tipos de sons, quanto à velocidade, pressão dos cilindros chapa $\mathrm{e}$ blanqueta, sucção do papel, funcionamento do motor principal, que devem ser diferenciados e monitorados por todo o tempo.

2. Impõe ao trabalhador grande exigência visual, pois os "pinos de registro", as "réguas" (para a correta margeação), o tinteiro com a sua regulagem e consistência de tinta e água (para o correto tom e sobreposição das cores), as corretas demarcações nas "provas" do impresso, diferentes grafismos, o deslizar do papel, a velocidade, os mostradores luminosos nos painéis, também devem ser constantemente monitorados.

3. Recepção de informações pelo tato também ocorrem, como no caso de diferentes texturas, como granulações de tinta, retoques na chapa, energia estática, umidade e imperfeições do papel, consistência da tinta, superaquecimento do equipamento.

4. O olfato, no caso de a máquina enviar mais ou menos água para o papel, estar queimando óleo, estar enviando excesso de tinta, ou por qualquer produto químico utilizado na impressão estar fora da quantidade adequada.

Por tudo isso, por essa complexidade cognitiva dispensada pelo trabalhador, existe, o problema "erro humano", causador de acidentes, permeando a segurança do trabalho; a frequência desse erro vai depender do funcionamento da referida interface homem-trabalho que, para o operador da máquina offset, está representada quase em sua totalidade por sua máquina.

MÉTODO OWAS E ERGOLÂNDIA (VERSÃO DE DEMONSTRAÇÃO)

$\mathrm{Na}$ investigação das possíveis posturas, que $16^{\circ}$ Ergodesign - Congresso Internacional de Ergonomia e Usabilidade de Interfaces Humano Tecnológica: Produto, Informações Ambientes Construídos e Transporte

$16^{\circ}$ USIHC - Congresso Internacional de Ergonomia e Usabilidade de Interfaces Humano Computador

CINAHPA | 2017 - Congresso Internacional de Ambientes Hipermídia para Aprendizagem.

adotadas pelos operadores das máquinas apresentariam maior incidência de distúrbios posturais, escolhemos as seis citadas nesta pesquisa, pois são realizadas durante as atividades de maior frequência dos operadores das máquinas:

1. Pegar o papel do carrinho para batê-lo no balcão. 2. Inserir o papel na máquina. 3. Fazer o acerto da chapa de impressão. 4. Regular, através de manivela, a altura da plataforma coletora de impressos para pegá-los prontos. 5. Verificar enquadramento das marcas de registros e retículas de tinta nas provas de impressos, utilizando a ferramenta "Conta fio". 6. Limpar a chapa e a blanqueta com líquidos apropriados.

Figura 1: $O$ operador pegando os impressos para em seguida batê-los no balcão.

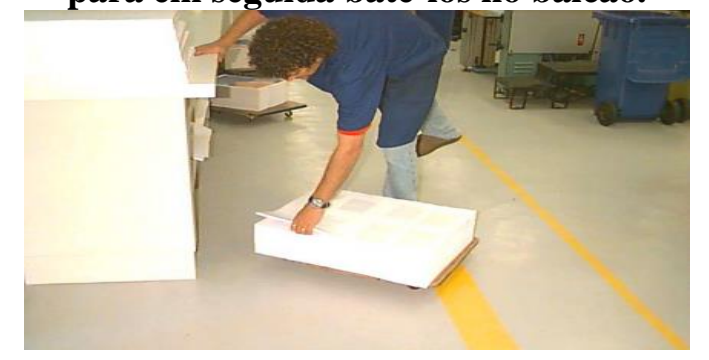

Fonte: Marcelo Reis Cezar (2005)

Figura 2: $O$ operador colocando papel na máquina para iniciar a impressão.

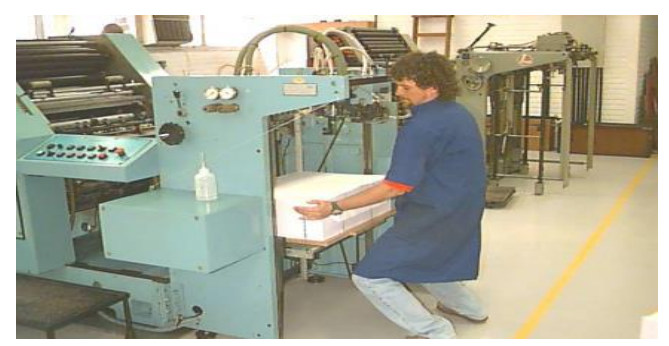

Fonte: Marcelo Reis Cezar (2005)

Figura 3: $O$ operador regulando a altura da mesa receptora de impressos para pegá-los em seguida. 


\section{$16^{\circ}$ \\ ERGODESIGN USIHC CINAHPA}

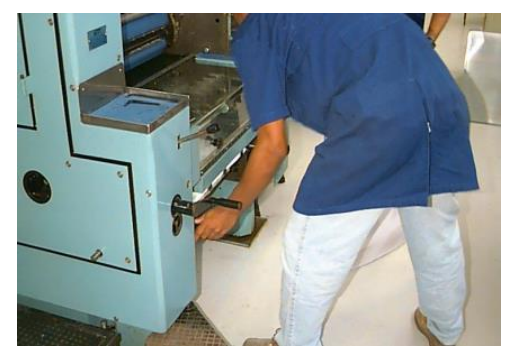

Fonte: Marcelo Reis Cezar (2005)

As posturas adotadas pelos operadores das máquinas (Figuras 1,2 e 3) para realizarem estas atividades foram observadas sistematicamente in loco e analisadas em registros fotográficos para então serem escolhidas para uma confirmação científica (utilização do método de análise postural OWAS).

Figura 4: Resultados processados no software.

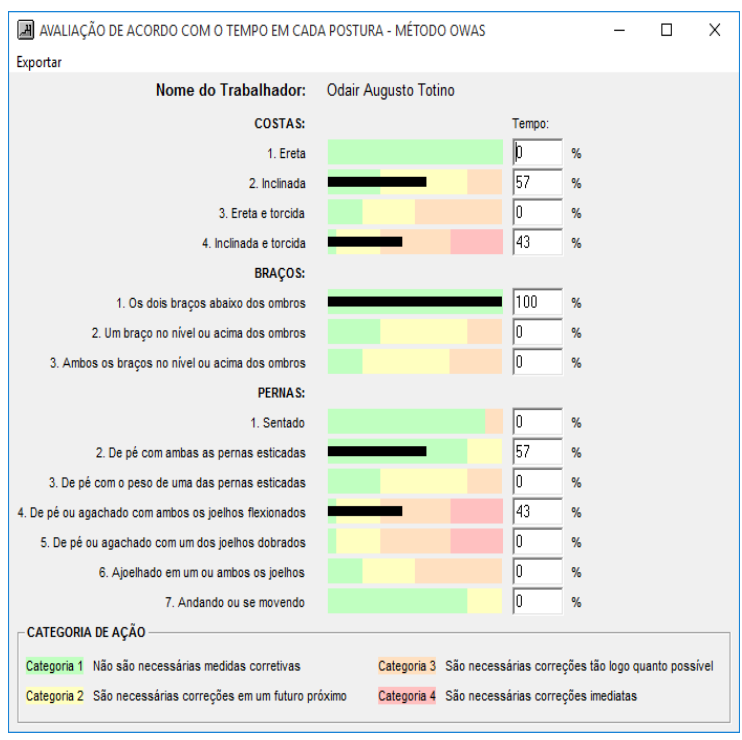

Fonte: Autor

As principais reclamações de desconforto dos operadores foram na região lombar, braços e mãos, além da cabeça e os olhos.

\section{Quadro 1: Questionário nórdico}

$16^{\circ}$ Ergodesign - Congresso Internacional de Ergonomia e Usabilidade de Interfaces Humano Tecnológica: Produto, Informações Ambientes Construídos e Transporte

$16^{\circ}$ USIHC - Congresso Internacional de Ergonomia e Usabilidade de Interfaces Humano Computador

CINAHPA | 2017 - Congresso Internacional de Ambientes Hipermídia para Aprendizagem.

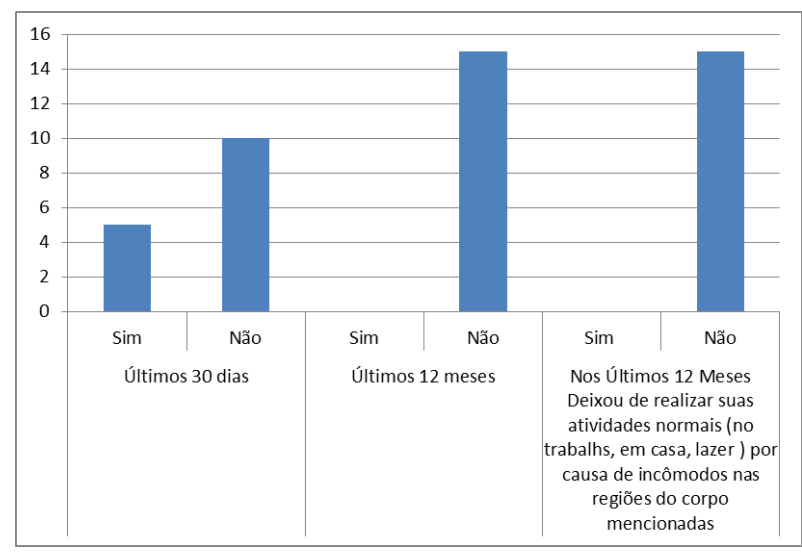

Fonte: Autor

O quadro acima (Quadro 1) é o resultado do questionário nórdico, onde foram perguntadas quais as áreas que mais causaram desconforto no operador e em que períodos ocorreram.

\section{Conclusões}

Através deste trabalho, pode-se constatar que o operador de máquina offset está inserido num contexto de risco musculoesquelético devido às posturas adotadas durante as suas atividades laborais no seu dia-a-dia profissional. Nesse sentido, os distúrbios posturais decorrentes de uma sobrecarga postural nos operadores de máquinas offset são um problema a ser resolvido para a população analisada através desta pesquisa, no contexto do desenvolvimento das suas atividades naquele local. Foram então observadas diversas posturas em todas as etapas da sua tarefa, concluindo-se que seis posturas, dentre todas, eram tidas como causadoras de distúrbios musculoesqueléticos afetando a coluna vertebral dos operadores.

De acordo com a avaliação postural realizada através do Método OWAS, pôde-se concluir que de uma população de três operadores de máquinas offset que compõem o setor de offset, todos estão inseridos num contexto de risco musculoesquelético, particularmente no que diz respeito às sobrecargas posturais que ocasionam sintomas no segmento lombar da coluna vertebral, traduzidos em categorias de risco. Quatro atividades traduzem posturas que estão enquadradas em uma categoria 2 de risco, sendo 


\section{$16^{\circ}$ \\ ERGODESIGN USIHC CINAHPA}

necessárias medidas corretivas em um futuro próximo, uma atividade traduz uma postura que está enquadrada em uma categoria 3 de risco, sendo preciso mudanças no método de trabalho assim que, finalmente, uma atividade traduzindo uma postura enquadrada na categoria 4 (máxima) de risco, devendo-se tomar medidas imediatas para a mudança da postura.

Segundo os resultados obtidos com esta pesquisa, tornam-se necessárias algumas considerações importantes inerentes à prevenção de transtorno postural; bem como manutenção e/ou melhoria do bem-estar geral no ambiente de trabalho para os profissionais operadores das máquinas offset. São elas:

- Atenção às leis que regem sua profissão e promoção de cursos de atualização profissional para esses trabalhadores;

- A correta aplicação da NR-17 (Ergonomia) no ambiente laboral, já tendo pensado no aprimoramento da referida NR;

Sugere-se, também que medidas preventivas sejam adotadas para o melhor desempenho do trabalho dos operadores das máquinas offset, como por exemplo: Manter-se fisicamente saudável, com uma atividade física regular; Procurar respeitar a jornada de trabalho, não sobrecarregando seu corpo; Realizar pausas para descanso durante a sua jornada de trabalho; Procurar manter em ordem o seu ambiente laboral

\section{Referências}

CEZAR, M.R. Atividade do operador de máquina offset. Universidade Federal de Santa Catarina. p.140, Florianópolis, 2006.

COUTO, H. A. Ergonomia aplicada ao trabalho: o manual técnico da máquina humana. Belo Horizonte: Ergo, 1995. v1.

DE VITTA, A. Atuação preventiva em fisioterapia. Edusc, Bauru. 1999.

ERGOLÂNDIA, disponível em: < http://www.fbfsistemas.com/ergonomia.html>. $16^{\circ}$ Ergodesign - Congresso Internacional de Ergonomia e Usabilidade de Interfaces Humano Tecnológica: Produto, Informações Ambientes Construídos e Transporte

$16^{\circ}$ USIHC - Congresso Internacional de Ergonomia e Usabilidade de Interfaces Humano Computador

CINAHPA | 2017 - Congresso Internacional de Ambientes Hipermídia para Aprendizagem.
FERREIRA JÚNIOR, M. Saúde no trabalho: temas básicos para o profissional que cuida da saúde dos trabalhadores. São Paulo: Roca, 2000.

Instituto Federal de Educação, Ciência e Tecnologia do Ceará. Ergonomia: Método de avaliação de postura OWAS 2011, disponível em $<$ https://pt.scribd.com/doc/60511370/Ergonomiametodo-Owas>, acesso em 07/05/2016

LATHAM, C. W. Offset: princípios básicos de impressão. AGGS: Rio-São Paulo, 1969.

MAGEE, D. J. Avaliação musculoesquelética. 3. ed. São Paulo: Manole, 2002.

MATTOS, U.; MÁSCULO, F.S.; Higiene e segurança do trabalho. São Paulo, Elsevier, 2011.

OWAS - Manual Ovako Working Analysing System. Helsinki: Finnish Institute of Occupational Health, 1990. Não paginado.

SANTOS FILHO, S., B.; BARRETO, S., M.. Atividade ocupacional e prevalência de dor osteomuscular em cirurgiões-dentistas de Belo Horizonte, Minas Gerais, Brasil: contribuição ao debate sobre os distúrbios osteomusculares relacionados ao trabalho. Cadernos de Saúde $\begin{array}{llllll}\text { Pública. } & \text { v. } & 17, & \text { n. } & 1, & 2001 .\end{array}$ 